\title{
A necropolítica na eminência do devir-negro do mundo
}

The necropolitics in the eminence of the world's becoming-black

\author{
Renato Noguera", Rogério Luis Seixas ${ }^{* *}$, Brunior Francisco Alves ${ }^{* * *}$
}

Resumo: A globalização atual trouxe uma infinidade de novos recursos tecnológicos e possibilidades para a realização de uma novo e tão esperado sonho de humanidade livre de todas as mazelas. Porém, como podemos notar, o mundo contemporâneo tem se mostrado, ao invés disso, uma máquina perversa de distribuição global das desigualdades, principalmente raciais anti-negros. Será por meio das críticas, conceitos e reflexões de Mbembe, Foucault e Agamben que buscaremos caracterizar esse mundo racistamente estruturado, desde a biopolítica, passando pela ideia de soberania e instituição da necropolítica, até as atuais possibilidades de um devir-negro do mundo.

Palavras-chave: Necropolítica; Biopolítica; Devir-negro do mundo; Soberania

\begin{abstract}
Today's globalization has brought a myriad of new technological resources and possibilities for the realization of a new and long-awaited dream of humanity free from all ills. However, as we can see, the contemporary world has shown itself instead to be a perverse machine of global distribution of inequalities, especially racial anti-blacks. It is through the critiques, concepts and reflections of Mbembe, Foucault and Agamben that we seek to characterize this racistly structured world, from biopolitics through the idea of sovereignty and the institution of necropoly, to the present possibilities of a becoming-black of the world.
\end{abstract}

Key words: Necropolitics; Biopolitics; Becoming-black of the world; Sovereignty

\section{Introdução: a natureza da democracia e da globalização}

A ideia moderna da democracia, tal como o próprio liberalismo, é, portanto, inseparável do projeto de globalização comercial, do qual a plantação e a colônia são o epicentro. Ora, sabemos que tanto a plantação como a colônia foram originariamente dispositivos raciais num cálculo geral sustentado pela relação de troca baseada na propriedade e no lucro ${ }^{1}$.

\footnotetext{
* Doutor em Filosofia, professor associado da Universidade Federal Rural do Rio de Janeiro (UFRRJ), titular do Programa de Pós-Graduação em Filosofia (PPGFil).

${ }^{*}$ Doutor em Filosofia pela UFRJ, pesquisador do grupo AFROSIN/UFRRJ.

${ }^{*}$ Graduado em Relações Internacionais e Mestre em Filosofia pela UFRRJ.

${ }^{1}$ MBEMBE, Crítica da Razão Negra, p. 142.
} 
No mundo contemporâneo, a ideia de democracia está estritamente ligada ao projeto de globalização. Será somente por meio da assimilação de sistemas democráticos por parte dos Estados que todas as dimensões sociais trazidas pela globalização, sejam elas positivas ou negativas, poderão atingir seu nível máximo de disseminação mundial. A questão emblemática é quanto a constatação das características racistas que tal modelo apresenta. Baseada nas relações de trocas organizadas dentro da lógica da propriedade e do lucro. A globalização atualiza os meios de produção e, principalmente, os dispositivos raciais herdados do regime escravocrata de plantações e colônias.

Achille Mbembe é o autor da citação acima que se encontra na recente obra Crítica da razão negra ${ }^{2}$. Em poucas palavras, o autor já evidencia sua crítica em relação à globalização, à democracia e suas características racistas. Alimentados por um falso discurso de liberdade, Mbembe, critica a sociedade em que vivemos por pregar a democracia, mas que é, na realidade, essencialmente escravagista.

Mbembe anuncia a eminência de um fenômeno social, o qual chama de "devir-negro do mundo", entendido, em poucas palavras, como a generalização das condições escravistas a todas as demais raças, outrora exclusivas para negros. O conceito de "devir negro do mundo" e as críticas raciais de Achille Mbembe nos servirão como paradigma e, somadas à Michel Foucault, Giorgio Agamben, Franz Fanon, Hannah Arendt, Friedrich Hegel, Thomas Hobbes e Abdias do Nascimento, como referência nas reflexões a respeito do mundo de hoje organizado a partir da biopolítica, da ideia de soberania, do biopoder transmutado em necropoder, do direito de morte na "necropolítica" e do próprio "devirnegro do mundo".

\section{Aspectos da biopolítica}

Achille Mbembe é, sem dúvida, um dos maiores expoentes da filosofia contemporânea. A sua crítica à racionalidade política, com destaque ao que passou a denominar de "razão negra", não pode ser entendida separadamente de um vasto debate acerca dos procedimentos e princípios filosóficos que asseguram um modelo dominante dessa mesma racionalidade política. Mbembe não deixa de estar em diálogo com pensadores como Thomas Hobbes, George Hegel, Sigmund Freud, Michel Foucault, Franz Fanon, Giorgio Agamben, dentre outros. Um dos desafios mbembeanos é analisar a biopolítica, apresentando seus limites e os mecanismos da racionalidade política. Afinal, a racionalidade política do Ocidente e, em certa medida do mundo globalizado, está acompanhada por conhecimentos técnicos e científicos que, paradoxalmente têm realizado as mais diversas formas de crimes e genocídios em massa e escalas diferentes, não obstante às livres de reflexão e contestações críticas. Nesse contexto, as estratégias de uma

\footnotetext{
${ }^{2}$ Ibidem.
} 
racionalidade biopolítica foram embasadas em diversas formas de discursos e saberes, percorrendo os mais variados campos de intervenção social, tais como o jurídico e o setor de saúde. Essa racionalidade funciona como forma de controle, de exclusão e eliminação.

Hegel, por sua vez, assumiu um ponto cego, ou ainda, uma falha no projeto "perfeito" da realização do Espírito Absoluto na vida política do Ocidente. Para o filósofo alemão ${ }^{3}$, a racionalidade política deve "abandonar os pobres ao seu destino e entregá-los à mendicidade pública”. Enquanto Mbembe vem, reinterpreta e ressalta que, no contexto neoliberal, tal abandono tem uma lógica racista anti-negra - assunto que voltaremos adiante. Para o momento, uma incursão na filosofia foucaultiana talvez seja um ponto de partida razoável para entendermos o projeto biopolítico da modernidade e, adiante, vislumbrar outras contribuições.

Michel Foucault, em "É preciso defender a sociedade" ${ }_{4}^{4}$, aponta uma transformação jurídico-política importante que se inicia nos séculos XVII e XVIII, intensificando-se e se estabelecendo de forma definitiva no século XIX. Acontecimento político que marca uma profunda mudança nos mecanismos de poder, qual seja, junto ao antigo direito do monarca de causar a morte e deixar viver, ocorre na modernidade a inversão deste direito, passandose a fazer viver e deixar morrer. Segundo Foucault ${ }^{5}$, "o direito de morte tenderá a se deslocar ou pelo menos, a se apoiar nas exigências de um poder que gere a vida e a se ordenar em função dos seus reclamos”. Note-se como que a noção de gestão da vida aparece nessa inversão do poder soberano, dado que agora, o exercício de poder se situa ao nível da vida e não mais relacionado, primordialmente, à morte. Conforme o próprio Foucault 6 , "pode-se dizer que esta nova tecnologia de poder, é cada vez menos de o direito de dar a morte e cada vez mais o direito de intervir para fazer viver. Desta forma, velho direito de causar a morte ou deixar viver, foi substituído por um poder de causar a vida ou devolver a morte".

O biopoder surge como suas novas técnicas que nem por isso excluem, de modo nenhum, a disciplina. Essa apenas passa a ser exercida em outro nível e escala diferentes, apresentando instrumentos e saberes totalmente diferentes das práticas da anatomopolítica disciplinar. Enquanto a disciplina se aplica sobre o homem-corpo, o biopoder possui, por sua vez, o homem-espécie como objeto de suas práticas - dirige-se ao homem enquanto ser vivo, o qual precisa ser gestado como uma biopolítica da espécie humana. Esses dois polos se entrelaçam para constituir a biopolítica da população.

Por sua vez, pode se entender o surgimento da biopolítica "como a maneira de se tentar lidar, a partir do século XVIII, racionalizar os problemas postos à prática

\footnotetext{
${ }^{3}$ HEGEL, Princípios de filosofia do direito, p. 209.

${ }^{4}$ FOUCAULT, É preciso Defender e Sociedade, 2006.

${ }^{5}$ Ibidem, p. 256.

${ }^{6}$ Ibidem, p. 264.
} 
governamental pelos fenômenos próprios a um conjunto de viventes constituídos em população"7. Este novo elemento denominado como população, passa a ser visto como problema político. Obtém-se, portanto, como instrumentos de conhecimento, os processos de natalidade, mortalidade e longevidade. O mapeamento de toda uma dinâmica de vida e morte do homem. Evidentemente, incluem-se as inerências que as doenças impõem, diminuindo a força de produção e causando despesas. Sintomaticamente surge outro aspecto de intervenção da biopolítica: se, por um lado, a doença revela uma baixa na produção e despesas com tratamento, por outro, a velhice revela que o indivíduo não mais constitui capacidade de produção. Nesse instante, aqueles saberes acerca de natalidade, mortalidade e longevidade, transformam-se em instrumentos de gestão. É importante salientar que, ao se levar em consideração o fator biológico humano, eleva-se a necessidade de conhecê-lo melhor. Quanto mais conhecido, melhor para modificá-lo, transformá-lo, manejá-lo.

Destacamos aqui outro ponto central para a nossa reflexão: a normalização biopolítica exercita-se visualizando, classificando e decidindo o que é normal ou não. Ou ainda se poderia até mesmo avaliar sobre o que vale a pena fazer viver ou deixar morrer. Segundo Giorgio Agamben, através da biopolítica pode-se determinar o que é normalmente humano e o que não é, o que pode contribuir para o fortalecimento da espécie ou afetar de modo nocivo. Este autor destaca que, na política ocidental, as decisões impostas no princípio de qualquer exercício de governamentalidade política estão sempre direcionadas sobre a vida. Sendo assim, afirma Agamben que "o conflito político decisivo, que governa todo outro conflito é, na nossa cultura, aquele entre a animalidade e a humanidade do homem. A política ocidental é, portanto, co-originariamente biopolítica" ${ }^{\text {. }}$ Esse autor também aponta que na dinâmica biopolítica descrita por Foucault, no exercício de poder viver e deixar morrer, se pode inserir outra formulação que descreva mais acertadamente a biopolítica exercida pelo racismo estatal no século XX: não mais fazer morrer nem fazer viver, mas sim "fazer sobreviver”. E é nessa condição de sobreviver que a espécie humana se animaliza e passa a apresentar uma condição de vida despolitizada e desprovida de direitos básicos. Essa é uma percepção de Agamben e que ele denominará nuta vida.

Numa remissão aos gregos e dialogando com Foucault e com a filósofa alemã Hannah Arendt, Agamben postula que a biopolítica se converte numa tanatopolítica. É a partir dessa ideia que o filósofo italiano situa dois registros para pensar a vida: zoé e bíos. Agamben lança mão do contexto cultural da Grécia antiga, onde zoé remete à vida natural, o simples viver indiferenciado comum a todos viventes: animais, animais humanos e divindades. Por sua vez, o caso de bíos estamos diante de uma leitura que remete aos escritos de Platão e Aristóteles interpelados por Arendt. Na Grécia antiga, a vida

\footnotetext{
${ }^{7}$ Ibidem p. 261.

${ }^{8}$ AGAMBEN, Homo Sacer: O poder soberano e a vida nua, p. 126-127.
} 
qualificada era bíos. Agamben ressalta um fenômeno decisivo: "o ingresso da zoé na esfera da polis, a politização a vida nua como tal constitui o evento decisivo da modernidade, que assinala uma transformação radical das categorias político-filosóficas do pensamento clássico" ". Diferente de Foucault, para Agamben a biopolítica é a marca fundamental de toda política praticada no Ocidente e não poderia, de forma nenhuma, estar restrita às transformações políticas europeias dos séculos XVIII e XIX. Por este motivo, ocorre a inclusão dos conceitos de "vida nua (zoê)" e o de homo sacer (matabilidade e insacrificabilidade).

Apesar de uma sumária apresentação que situa alguns aspectos distintos entre Foucault e Agamben em relação às concepções de biopolítica, é importante destacar que ambos não dispensam atenção ao fenômeno da escravização negra e do genocídio dos povos originários da América. Enquanto Foucault trata do racismo no contexto do biopoder, Agamben não deixa de trazer luzes sobre uma "raça matável". Porém, há de se observar que nenhum dos dois trabalha as tecnologias políticas nas relações entre Europa e outros continentes. Caberá ao filósofo camaronês, Achille Mbembe, trazer, por meio da "razão negra”, tal reflexão crítica intercontinental para a discussão da biopolítica. Por "razão negra" se deve entender: uma série de discursos e práticas articuladamente engendrados para fazer valer algo que a racionalidade política moderna não poderia incluir na cidadania ou na vida qualificada. Como acrescenta o próprio Mbembe:

Por este termo ambíguo e polêmico, designamos várias coisas ao mesmo tempo: imagens do saber; um modelo de exploração e depredação; um paradigma da submissão e das modalidades da sua superação, e, por fim, um complexo psiconírico. Esta espécie de enorme jaula, na verdade uma complexa rede de desdobramentos, de incertezas e de equívocos, tem a raça como enquadramento. ${ }^{10}$

\section{A questão da soberania}

O filósofo inglês Thomas Hobbes consagrou a fórmula moderna ao afirmar que o poder soberano é resultado de um contrato estabelecido entre todos integrantes de uma sociedade. Em suma, trata-se de um acordo coletivo que transfere o poder igualitário de todas as pessoas para entidade centralizada que se torna politicamente autorizada a decidir em nome de todos.

Por sua vez, ao entender que a questão da soberania sempre esteve muito atrelada à dimensão do direito, Michel Foucault propõe um deslocamento e recoloca o problema fora

\footnotetext{
${ }^{9}$ Ibidem, p. 12.

${ }^{10}$ MBEMBE, Crítica da Razão Negra, 25.
} 
do terreno jurídico. Nesse Sentido, Foucault afirma que "Por longo tempo um dos privilégios característicos do poder soberano foi o direito de vida e de morte" ${ }^{11}$.Foi preciso deslocar a soberania do contexto da teoria clássica. A partir dessa mudança, Foucault ressalta o caráter difuso do poder:

O poder não existe. Quero dizer o seguinte: a ideia de que existe, em um determinado lugar, ou emanando de um determinado ponto, algo que é um poder, me parece baseada em uma análise enganosa e que, em todo caso, não dá conta de um número considerável de fenômenos. Na realidade, o poder é um feixe de relações, mais ou menos organizado, mais ou menos piramidalizado, mais ou menos coordenado. Portanto, o problema não é de construir uma teoria do coordenado. Portanto, o problema não é de construir uma teoria do poder. ${ }^{12}$

Com isso, Foucault contribui para uma perspectiva mais ampla do poder, deixando de lado a hipótese repressiva, ou ainda, diminuindo o seu alcance. Esse aspecto do poder favorecer a compreensão da biopolítica e do biopoder - como veremos adiante. e, em certa medida, contribuir para as considerações de Agamben que ressaltam um paradoxo radical em relação ao poder soberano. O debate da perspectiva agambeniana surge para confrontar o paradoxo do poder soberano, de modo que o filósofo italiano traz o Estado de exceção como uma dimensão da soberania.

Com referência ao Estado de exceção, Mbembe destaca, no capítulo do ensaio Necropolítica intitulado "Política, o trabalho da morte e o devir sujeito", o seu uso em discussões envolvendo as experiências dos regimes totalitários e os campos de extermínio. Observe-se que o pensador camaronês propõe que "a Modernidade sempre esteve nas origens de diferentes e diversificados conceitos de soberania e, por conseguinte, embasando-se na prática da biopolítica" ${ }^{13}$ não se limitando ao acontecimento do extermínio judeu e dos governos totalitários.

Quando Mbembe estuda os regimes pós-coloniais africanos, de saída, já aponta para uma relação direta entre soberania e propriedade. Em termos simples seria o desmonte da coisa pública em função da coisa privada para que a gestão dos meios que garantem aquilo que - nos termos de Foucault em "Em defesa da sociedade" - fazem o corte entre o que deve viver e morrer estejam ligadas a interesses econômicos e não de bem-estar geral.

Achille Mbembe apresenta a ideia de que o sentido de soberania ganha sua expressão máxima no poder e na capacidade do soberano decidir quem deve morrer e quem pode viver - Questão que trataremos mais adiante.

\footnotetext{
${ }^{11}$ FOUCAULT, É Preciso Defender a Sociedade, p. 257.

${ }^{12}$ Ibidem, p. 248.

${ }^{13}$ MBEMBE, A. Necropolítica: Biopoder, soberania, estado de exceção, política da morte, p. 8.
} 
Em vez de considerar a razão a verdade do sujeito, podemos olhar para outras categorias fundadoras menos abstratas e mais palpáveis, tais como a vida e a morte" ${ }^{14}$. Ao esclarecer sobre um dos seus principais objetivos, Mbembe afirma que sua preocupação não se direciona as formas de soberania, cujo projeto central é a luta pela autonomia dos indivíduos, mas sim "a instrumentalização generalizada da existência humana e a destruição material de corpos humanos e populações" ${ }^{15}$.

Sem dúvida, além de manter um diálogo estreito com Foucault e, em certa medida, com Agamben, não é exagero situar Achille Mbembe como um discípulo de Frantz Fanon. O filósofo camaronês é interlocutor do debate filosófico de descolonização, das incursões críticas que reinterpretam o pensamento hegeliano e a psicanálise dentro de uma perspectiva de combate ao racismo. É a partir dessa perspectiva mbembeana, que Noguera relaciona a crítica de Mbembe em relação à derrocada da Europa com os mesmos pensamentos descentralizadores herdados de Fanon:

Em Os condenados da terra, Fanon ensina que a centralidade europeia em nome de um projeto de emancipação da humanidade trai a si mesma. A Europa propôs a "libertação do mundo", mas condenou a si e a todos, à medida que se enredou num fundamentalismo perigoso e narcísico que só reconhece um modelo civilizatório. O Mbembe segue na trilha fanoniana, a Europa está em declínio e não pode mais arvorar-se como centro de gravidade do mundo. O seu projeto de integração. fracassou quando o quesito é a realização da promessa iluminista, sua aparente dignidade foi perdida numa trilha de promessas não cumpridas. ${ }^{16}$

\section{A necropolítica}

Antes de adentramos no conceito de "necropolítica” de Mbembe, faz-se necessária uma caracterização do conceito foucaultiano de "biopoder". Segundo Foucault, o exercício do biopoder, "elemento indispensável ao desenvolvimento do capitalismo, garantiu a inserção controlada dos corpos no aparelho de produção, ajustando também a população aos processos econômicos” ${ }^{17}$. Depreende-se do autor que, o biopoder, como instância organizacional, rege, dentre diversos outros instrumentos, a biopolítica. É bem verdade que Mbembe, de certo modo, em suas críticas até parte do conceito de biopoder

\footnotetext{
${ }^{14}$ Ibidem, p.11.

${ }^{15}$ Ibidem, p.10-11.

${ }^{16}$ NOGUERA, Dos condenados da terra à necropolítica: diálogos filosóficos entre Frantz Fanon e Achille Mbembe, p. 63-64.

${ }^{17}$ FOUCAULT, M. Nascimento da Biopolítica, p. 152.
} 
foucaultiano, mas com o objetivo de desafiá-lo ao máximo, "explorando sua relação com a noção de soberania (imperium) e o Estado de exceção" ${ }^{18}$.

Aparentemente, Mbembe concorda com a suficiência do conceito de biopoder foucaultiano para explicar os fenômenos que implicam nesse poder soberano sobre a vida. Contudo, observa-se ser mesmo aparente esta concordância, visto que o autor destaca diferentes questões que põem em dúvida a pertinência dessa concepção de biopoder. Dentre todas essas questões, destacamos uma como sendo especialmente vital: Essa noção de biopoder é suficiente para contabilizar as formas contemporâneas em que o político, por meio da guerra, da resistência ou da luta contra o terror, faz do inimigo seu objetivo primeiro e absoluto? Em outros termos, questionamos se a noção formulada por Foucault, pode permitir a compreensão das maneiras contemporâneas em que a política, através da guerra, faz do assassinato do inimigo, o "objetivo primeiro e absoluto" ${ }^{19}$. Assim, Mbembe apresenta outra proposta em seu ensaio: a guerra como forma de atingir a soberania, enquanto um modo de exercer o direto de matar. Partindo desta indagação, o autor formula outra importante questão para a condição política contemporânea: como a vida, a morte e o corpo humano estão inseridos na ordem do poder?

Formulando o conceito de necropoder, que concebe uma política de produção de morte, Achille Mbembe discorda e se propõe a superar o conceito de "necropolítica" de Michel Foucault que, por sua vez, se referenciava mais diretamente ao aumento deliberado do risco de morte. Sempre provocador, o autor africano propõe "uma leitura da política, da soberania e do sujeito, diferente da modernidade. Em vez de considerar a razão a verdade do sujeito, podemos olhar para outras categorias fundadoras menos abstratas e mais palpáveis, tais como a vida e a morte” ${ }^{20}$.

Mas o que significa necropoder? Pode-se descrevê-lo em síntese enquanto o conjunto de tecnologias políticas que atuam para estabelecer a gestão e controle das populações e do indivíduo.Com o necropoder, tem-se uma política de gestão da morte, denominada de necropolítica e podendo ser descrita enquanto a submissão da vida ao poder da morte, apresentando-se contrariamente também à biopolítica foucaultiana que, por sua vez, se concentra em fazer viver e deixar morrer. Qualifica-se assim a necropolítica enquanto uma "política da morte", ilustrando que "a noção de biopoder é insuficiente para dar conta das formas contemporâneas de submissão da vida ao poder da morte" ${ }^{21}$.

Assevere-se que, de acordo com a concepção foucaultiano, a biopolítica se assemelha a um trabalho de vida, porque o que está em jogo é constantemente produzir a vida, sejam tanto os indivíduos dóceis politicamente e úteis produtivamente, quanto ou as populações sadias que garantam uma governamentalidade eficiente, visando assim um

\footnotetext{
${ }^{18}$ MBEMBE, Necropolítica. Biopoder, soberania, estado de exceção, política da morte, p. 7.

${ }^{19}$ Ibidem, p. 6.

${ }^{20}$ Ibidem, p. 11.

${ }^{21}$ Ibidem, p. 71.
} 
esquecimento da morte. Todavia, em desacordo com esta concepção foucaultiana, Mbembe defende que no contexto político mais contemporâneo, caracterizado pelo Estado de exceção constituindo-se como regra, a biopolítica se converte em necropolítica, isto é, no trabalho de morte. Como afirma o autor:

Propus a noção de necropolítica e necropoder para explicar as várias maneiras pelas quais, em nosso mundo contemporâneo, armas de fogo são implantadas no interesse da destruição máxima de pessoas e da criação de "mundos de morte", formas novas e únicas da existência social, nas quais vastas populações são submetidas a condições de vida que lhes conferem o status de mortos-vivos. ${ }^{22}$

Dessa forma, em termos de política contemporânea, aventa-se a passagem da biopolítica para uma necropolítica, não mais como uma política voltada para a produção da vida, mas cujo objetivo principal é a aniquilação em larga escala, que define a soberania como o poder de determinar quem pode viver e quem deve ser morto. Aqui a tendência para o "trabalho morto" na produção de valor encontra o "trabalho de morte" da política. O controle sobre as condições de vida e morte são atos soberanos. Pode-se constatar que a concepção de necropolítica, ultrapassa a percepção de biopoder foucaultiana, visto que se estabelece as circunstâncias práticas do direito soberano de matar, da permissão para viver e na exposição à morte. Acrescente-se que o exercício do necropoder expressa um pouco da herança da soberania política Schmittiana, ou seja, encarna a prerrogativa do soberano em declarar a exceção dos direitos e garantias dos sujeitos, reconhecidos como inimigos, podendo inclusive torná-los matáveis em nome da segurança do corpo social. Um fator importante tratado por Mbembe que "examina essas trajetórias pelas quais o Estado de exceção e a relação de inimizade tornaram-se a base normativa do direito de matar. Em tais instâncias, o poder continuamente se refere e apela à exceção, à emergência e uma noção ficcional do inimigo" ${ }^{23}$. Inimigo tratado enquanto um outro que se torna uma ameaça a ser eliminada, segundo um tipo de norma ou regra que o torna passível de ser morto.

A gestão biopolítica se inscreve na história do liberalismo político. Citando o pensador: A prática de governar do poder soberano é agora, recoberta pela "capacidade de administração dos corpos e pela gestão calculista da vida” ${ }^{24}$. O exercício do biopoder, "elemento indispensável ao desenvolvimento do capitalismo, garantiu a inserção controlada dos corpos no aparelho de produção, ajustando também a população aos processos econômicos”25.

\footnotetext{
${ }^{22}$ Ibidem.

${ }^{23}$ Ibidem, p. 17.

${ }^{24}$ FOUCAULT, Nascimento da Biopolítica, p. 150.

${ }^{25}$ Ibidem, p. 152.
} 
Hegel é destacado por Mbembe como o pensador que define a vida do espírito como aquela que não teme a morte, mas a pressupõe e vive com ela. A política é descrita como "a morte que vive uma vida humana" ${ }^{26}$. Em Hegel, o autor observa assim uma relação "entre absoluto e soberania: o arriscar a totalidade de uma vida" ${ }^{27}$. Destaca-se uma relação dialética hegeliana entre a morte e o devir sujeito. A partir desta relação, Mbembe ressalta o que denomina como bipartidarismo de negatividade, constituído por dois fatores: a negação da natureza pelo humano e a transformação desta por meio do trabalho e da luta. Essa negação é observada em Hegel como a transformação de mundo, onde o ser humano cria um mundo, mas expõe-se a sua própria negatividade. Identifica-se em Hegel o reconhecimento da morte humana como voluntária, sendo assim lançado no movimento da história, sustentando o trabalho da morte. Nesse sentido, "Há uma ligação direta entre morte, soberania e sujeito" 28 .

Bataille é utilizado para confrontar Hegel, no sentido que para aquele pensador, a morte e a soberania representam uma troca e superabundância, ou em outros termos, "um excesso e a vida é o domínio da soberania, se constituindo assim a morte como dispêndio irreversível e radical, sem apresentar qualquer tipo de negatividade. A morte é encarada como o princípio da antieconomia” ${ }^{29}$. A percepção de Bataille sobre soberania e morte que mais parece interessar a Mbembe é sua característica de violação de proibições, reabrindo a questão referente aos limites da política e recusando que essa só possa ser desenvolvida pela dialética da razão. A política desorienta e transgredi a noção de limite. Citando o pensador:

Ao tratar a soberania como a violação de proibições, Bataille reabre a questão dos limites da política, nesse caso, não é o avanço de um movimento dialético da razão. A política só pode ser traçada como uma transgressão em espiral, como aquela diferença que desorienta a própria ideia de limite ${ }^{30}$.

Mas qual é o sentido de liberalismo aqui já mencionado? Segundo o pensador francês, Michel Foucault, esse necessita ser interpretado como uma prática refletida de governo como uma "maneira de fazer" orientada para objetivos e se regulando por uma reflexão contínua - não como uma teoria econômica ou jurídica, mas sim um "princípio regulador político-administrativo que parte da premissa que sempre se governa demais" 31 .Objetiva-se, deste modo, reformar, racionalizar e limitar os abusos do se governar demais. Por este motivo, de acordo com o autor, "o liberalismo deve ser

\footnotetext{
${ }^{26}$ MBEMBE, Necropolítica. Biopoder, soberania, estado de exceção, política da morte, p. 12.

${ }^{27}$ Ibidem, p. 13.

${ }^{28}$ Ibidem.

${ }^{29}$ Ibidem, p. 14.

${ }^{30}$ Ibidem, p. 16

${ }^{31}$ FOUCAULT, Nascimento da Biopolítica, p. 45-46.
} 
analisado, como princípio e método de racionalização do exercício de governo racionalização que obedece, e aí está sua especificidade, à regra interna da economia máxima" ${ }^{2}$. Observamos como a presença da biopolítica se faz notar, quando ao se analisar as peculiaridades desta racionalidade liberal de governo, desenvolve-se e aprofunda-se de fato a problematização de um exercício de poder sobre a vida, evidenciando-se a formação de uma política gestora sobre as condições mais viáveis e positivas de se agenciar a vida do corpo-população, a partir exatamente da questão da governamentalidade e do liberalismo, passando é claro para o_neoliberalismo e suas formas de gestão atuais.

Evidencia-se que a racionalidade política da arte de governar neoliberal, se exerce no sentido da generalização da forma política do mercado para todo o corpo social; de modo que a economia de mercado funcionará como princípio de inteligibilidade das relações sociais e condutas individuais. Com o neoliberalismo, a economia será uma análise da programação estratégica das atividades e dos comportamentos dos indivíduos. Desse modo, como se produzir e se acumular o capital humano? Qual sua composição? São questões que envolvem esta racionalidade governamental, indicando-se o papel do mercado como que exercendo um tribunal econômico permanente das metas da economia política. A prática de governar do poder soberano é agora, recoberta pela "capacidade de administração dos corpos e pela gestão calculista da vida”. ${ }^{33}$

Traçando a relação entre biopolítica e neoliberalismo, pode-se afirmar que a noção da ação política da morte, ou a necropolítica, se configura enquanto a forma política mais adequada ao neoliberalismo atual, no sentido de que atende a um dos seus objetivos principais, que Mbembe captou com grande perspicácia: “a destruição material dos corpos e populações humanas julgados como descartáveis e supérfluos" ${ }^{34}$. Em seu ensaio Crítica da Razão Negra, o autor descreve esses corpos supérfluos e descartáveis, que são assim classificados, quando as suas capacidades de trabalho diminuem ou cessam, ou ainda, ao não se constituírem mais como necessários ao modo de reprodução próprio ao neoliberalismo. O autor afirma que tal situação representa a inexistência de trabalhadores propriamente ditos. Significa dizer que no quadro neoliberal,

(...) só existem nômades do trabalho, sendo estes relegados a uma humanidade supérflua, entregues ao abandono e sem qualquer utilidade para o funcionamento do capital, tornando-se dispensáveis e até mesmo, convertendo-se em vidas matáveis, exatamente por se tornarem inúteis ${ }^{35}$.

Verifica-se assim a condição de "vida nua", desprovida de qualquer valor para a produção e consumo, “assinalando o ponto em que a biopolítica converte-se

\footnotetext{
${ }^{32}$ FOUCAULT, Resumo dos Cursos do Collége de France (1970-1982), p. 90.

${ }^{33}$ FOUCAULT, Nascimento da Biopolítica, p. 150.

${ }^{34}$ MBEMBE, Crítica da Razão Negra, p. 17.

${ }^{35}$ Ibidem.
} 
necessariamente em tanatopolítica" 36 ou, como destaca Mbembe, "a necropolítica enquanto política da morte”. Nessa situação, se a necropolítica se coaduna com a condição do Estado de exceção, como aponta o autor camaronês, pode-se distribuir de forma excludente e desigual recursos políticos e econômicos, exercendo-se um exercício de veto por parte do soberano, sobre as condições de vida dos que são classificados como descartáveis e, consequentemente, estabelece-se um poder de decisão de exposição à morte dos grupos considerados impuros ou marginalizados.

Nesse contexto surge o racismo de Estado, que possui como base a decisão sobre quem deve viver e quem deve morrer. Gerenciam-se modos de eliminação dos indesejáveis, dos inúteis, os descartáveis, para o bom funcionamento da sociedade-empresa. Práticas de eliminação que passam pela exclusão de determinados grupos ou indivíduos de seus ditos direitos, por exemplo, à assistência social e serviços de saúde, por serem considerados não gestáveis. Ou como destaca o próprio Foucault, "O fato de expor pessoas à morte, de multiplicar para elas o risco de morte, ou, pura e simplesmente, a morte política, a expulsão, a exclusão, etc." ${ }^{37}$. O racismo é a condição para a prática do direito de morte numa configuração biopolítica e neoliberal do poder. O extermínio e os massacres são justificados segundo a lógica do biopoder, predominante na racionalidade política atual. Pode-se descrever aqui um mecanismo para promoção da vida, visando o fortalecimento da espécie, explicando a até mesmo o exercício da violência biopolítica que causa a morte dos inferiores e indesejáveis. Como cita o autor, "Quanto mais numerosos forem os que morrem entre nós, mais pura será a raça a que pertencemos”. ${ }^{38}$

Ao relacionar a noção de biopoder foucaultiana aos conceitos de Estado de exceção e Estado de emergência Mbembe destaca que o "biopoder parece funcionar mediante a divisão entre pessoas que devem morrer e as que devem viver." ${ }^{39}$.O autor observa o exercício desse poder controlando o campo biológico, afirmando-se a subdivisão da população gerida biopoliticamente, em grupos e subgrupos, mas efetuando-se marcadamente, uma divisão biológica intensa entre estes. Essa condição revela o real sentido de "racismo" presente na reflexão de Foucault ${ }^{40}$. Mbembe assevera que a noção de biopoder foucultinana, expressa um caráter necessariamente racista, uma vez que o racismo se estabelece enquanto condição prévia essencial para conferir ao Estado o poder de matar. Assim sendo, o autor africano, ao tratar do conceito política de morte, concorda com Foucault que a erradicação de subgrupos de uma população biopoliticamente gerenciada, configura-se como uma forma justificável de preocupação com a pureza racial ou a saúde racial de uma determinada sociedade.

\footnotetext{
${ }^{36}$ AGAMBEN, Homo Sacer: o poder soberano e a vida nua, p. 138.

${ }^{37}$ FOUCAULT, É Preciso Defender a Sociedade, p. 273.

${ }^{38}$ Ibidem, p. 274.

${ }^{39}$ MBEMBE, Necropolítica. Biopoder, soberania, estado de exceção, política da morte, p. 17.

${ }^{40}$ Ibidem.
} 
Para Mbembe, não seria novidade que a raça, assim como o racismo, possua um lugar de destaque na racionalidade do exercício do biopoder, pois afinal, "a raça foi a sombra sempre presente no pensamento e na prática das políticas do Ocidente, especialmente quando se trata de imaginar a desumanidade de povos estrangeiros ou a dominação a ser exercida sobre eles" ${ }^{41}$. Mbembe acrescenta que em termos foucaultianos "o racismo é acima de tudo uma tecnologia destinada a permitir o exercício do biopoder" ${ }^{42}$. Sua função seria a de regular a distribuição da morte e possibilitar as funções biopolíticas de matar por parte do Estado. Há um exercício de fazer matar sob uma perspectiva que decide justamente em que momento uma vida deixa de ser política e economicamente relevante e, consequentemente, pode ser eliminada do tecido social. Exerce-se o "trabalho de morte" da política sobre os indivíduos que começam a sobrar diante da estrutura neoliberal atual, tornando-se pouco rentáveis, não são mais requisitados a despenderem sua força de trabalho no interior de um processo produtivo amplo.

Quando nos reportamos a uma sociedade como a brasileira, marcada pela questão vergonhosamente histórica da escravidão e, por consequência, as diversas formas de racismo, dizer que observamos muitos sinais das práticas de uma violência depuradora da necropolítica contra os corpos negros não se configura como um exagero. Como observa Abdias do Nascimento em seu livro O genocídio do povo negro, "a tentativa de branqueamento da raça foi uma estratégia de genocídio contra a população negra que era maioria”. 43

Abdias alerta que durante os tempos de escravidão, "esta política de embranquecer a população estruturava-se de forma a limitar de qualquer modo o crescimento da população negra" ${ }^{44}$. Não se pode negar que tal estratégia de embranquecer a população visando eliminar a "ameaça da raça negra”, inferior e nociva, para a saúde do corpo social, muito se aproxima de uma técnica biopolítica de depuração eugênica. A política de branqueamento conjugava a seleção de imigrantes europeus, assim como o estímulo a miscigenação sucessivas em que o sangue branco, por ser considerado naturalmente superior, e sobreporia ao sangue negro, considerado impuro e inferior.

Os corpos negros são ainda relegados em nossa sociedade a uma condição subalterna, marginal, colonizada e à exclusão geográfica das comunidades, locais onde, como observa Noguera, "a morte de alguns é rotina comum, um luto que não se torna público e noticiado. Faz parte da política” ${ }^{45}$. Permanecendo assim a prática do genocídio do povo negro, apontado por Abdias do Nascimento. Fazendo referência a Mbembe

\footnotetext{
${ }^{41}$ Ibidem, p. 18.

${ }^{42}$ Ibidem, p.18-19.

${ }^{43}$ NASCIMENTO, O genocídio do negro brasileiro. Processo de um Racismo Mascarado, p. 93.

${ }^{44}$ Ibidem, p. 96.

${ }^{45}$ NOGUERA, Dos condenados da terra à necropolítica: diálogos filosóficos entre Frantz Fanon e Achille Mbembe, p. 72 .
} 
quando desenvolve sua análise sobre a relação entre morte e vida, instaurando-se a partir do sistema de plantation, esse genocídio apresenta a forma peculiar de terror que se apresenta como a "concatenação entre biopoder, o Estado de exceção e o Estado de sítio. A raça é, mais uma vez, crucial para esse encadeamento" ${ }^{46}$, como afirma Noguera:

Talvez seja oportuno repensarmos filosoficamente as condições de possibilidade da emergência da necropolítica, se quisermos problematizar possibilidades de resistências. O maior inconveniente? As práticas necropolíticas têm repetidamente dito que o luto não é um direito de todos. Mas, um privilégio dos bons. ${ }^{47}$

\section{O devir-negro do mundo}

$\mathrm{O}$ ponto interessante sobre a tese de um devir-negro no mundo nos parece ser justamente essa população que está vulnerável sob esse poder de coação, de extermínio. A diferença marcante entre o modo como Mbembe demarcará essa raça não participa diretamente da fantasia da raça criada pela modernidade ocidental. Tão pouco encontra ares de imprecisão na sua definição. É mister lembrar que, para Mbembe, a raça, bem como o Negro nunca foram definidos de uma só maneira imutável ao longo do tempo. E ele argumenta no sentido desse devir-negro não ser baseado na fantasia ocidental chamada raça.

Pela primeira vez na história da humanidade, o nome negro deixa de remeter unicamente para a condição atribuída aos genes de origem africana durante o primeiro capitalismo (predações de toda a espécie, desapossamento da autodeterminação e, sobretudo, das duas matrizes do possível que são o futuro e o tempo). A este novo caráter descartável e solúvel, à sua institucionalização enquanto padrão de vida e à sua generalização ao mundo inteiro, chamamos devir negro do mundo ${ }^{48}$.

Retomando a primeira parte do ensaio Crítica da razão negra, denominado como devir-negro, Mbembe disserta sobre o neoliberalismo caracterizando-o como "a época ao longo da qual o tempo (curto) se presta a ser convertido em força reprodutiva da formadinheiro. Tendo o capital atingido o seu ponto de fuga máximo, desencadeou-se um movimento de escalada" ${ }^{49}$. O autor ressalta ainda que essa forma atual de capitalismo desencadeia um acontecimento essencial: a fusão entre capitalismo e animismo, resultando

\footnotetext{
${ }^{46}$ MBEMBE, Necropolítica. Biopoder, soberania, estado de exceção, política da morte, p. 31.

${ }^{47}$ NOGUERA, Dos condenados da terra à necropolítica: diálogos filosóficos entre Frantz Fanon e Achille Mbembe, p. 72.

${ }^{48}$ MBEMBE, Crítica da Razão Negra, p. 18.

${ }^{49}$ Ibidem, p. 15.
} 
em algumas consequências determinantes para a futura compreensão da raça e do racismo. Desde logo, os riscos sistemáticos aos quais os negros escravizados foram expostos durante o primeiro capitalismo constituem agora, "se não a norma, pelo menos o quinhão de todas as humanidades subalternas, ou dito de outra forma, passíveis de serem excluídas e descartadas" ${ }^{50}$. Por meio do "devir-negro do mundo", Mbembe destaca o caráter de "universalização da condição negra como simultânea ao surgimento de práticas imperiais inéditas, ainda tributárias tanto das lógicas escravagistas de captura e predação, como das lógicas coloniais de ocupação e exploração, incluindo as guerras civis ou raciais de épocas passadas" ${ }^{51}$.

É preciso compreender que, na análise do camaronês, o negro é uma invenção elaborada em uma plataforma racista e que se manterá funcionando enquanto não o retirarmos dela. A afirmação de que o nome negro deixa de remeter àquele lugar comum do qual sempre partíamos nossas análises raciais causa estranhamento e suscita um empenho para a compreensão desse novo lugar, sem cairmos no reducionismo simplista de que as teias das dívidas que o neoliberalismo vem construindo através da história da colonização dos povos negros e da escravização, da baixa monetarização da sua força de trabalho e do saqueamento estrutural de suas riquezas materiais e culturais.

Apesar de "Sobre o Governo Privado Indireto" 52 ser um texto anterior à Crítica da razão negra, acreditamos que a análise de Mbembe do campo democrático, pela perspectiva que concebe raça como um dos fatores de estratificação social, é fundamental por nos permitir avaliar a condição de inserção do corpo negro dentro da política moderna, da globalização e de um eminente devir-negro do mundo.

\section{Conclusões parciais}

O filósofo camaronês Achille Mbembe faz uma análise política que, mesmo em um diálogo com Foucault e Agamben por conta da releitura da biopolítica, suas análises se aproximam mais do filósofo martinicano Frantz Fanon. Tanto Mbembe como Fanon, diferentemente de Foucault e Agamben, colocam o racismo antinegro no centro de suas análises.

Se Foucault indicou uma ligação direta do biopoder com capitalismo. Vale dizer que Mbembe articula necropoder e neoliberalismo. As condições históricas ganham outros contornos. Afinal, para Foucault o caráter racista do Estado biopolítico tinha como exemplo o nazismo. Seria este, para o pensador francês, o exemplo máximo. Era o caso de uma sociedade universalmente disciplinar que repartiu o antigo poder soberano de matar.

\footnotetext{
${ }^{50}$ Ibidem, p. 14.

${ }^{51}$ Ibidem, p. 15.

${ }^{52}$ MBEMBE, Necropolítica seguido de Sobre el gobierno privado indirecto, 2011.
} 
Além do braço armado do Estado nazista, o exército alemão; um cidadão comum podia denunciar uma família judia escondida e exercer o poder de morte, ainda que indiretamente.

Agamben traz contribuições interessantes, à medida que denuncia que a democracia é incapaz de resistir ao Estado de exceção que vai decretar mortes. Afinal, “decisivo é, sobretudo, o fato de que, lado a lado com o processo pelo qual a exceção se torna em todos os lugares a regra" ${ }^{53}$. Ora, o espaço da vida nua que estava à margem, agora está dentro do ordenamento jurídico-político. Agamben também observa o nazismo e situa a eutanásia como um dispositivo que serviu como serviço de saúde do corpo biológico nacional.

Mbembe, por sua vez, postula que o poder soberano não se ocupa mais da vida; mas, somente da morte. Enquanto o campo de concentração nazista é tido por Foucault e Agamben como espaço paradigmático do biopoder, Mbembe, para uma leitura mundial das relações de poder, denuncia o Atlântico Negro (o fluxo de deslocamento forçado de milhões de pessoas africanas para a América e Europa do século XV até XIX), o genocídio dos povos originários da América e a escravização negra como marcos máximo do biopoder. O próprio desenvolvimento do capitalismo não pode ser destacado desses eventos. Foi a hiper-exploração da África e da América pela Europa que tornou possível um estágio de acumulação do capital nunca visto e o estabelecimento da Europa como centro econômico-financeiro do mundo até o fim da $2^{\underline{a}}$ Guerra.

Mbembe chama atenção para a retomada do modelo exploratório da escravização negra. Aqui encontramos uma novidade, talvez isso faça de Mbembe um dos pensadores mais interessantes da atualidade. Nas reflexões sobre o "devir-negro do mundo", encontramos a afirmação de o liberalismo e a escravização como coextensivos, ainda que o trabalho assalariado e direitos trabalhistas tenham certo espaço dentro do regime. $O$ neoliberalismo é a radicalização desse projeto à medida que significa um projeto de eliminação das garantias totais. É a proposta de transformar o trabalhador do contexto neoliberal naquela mesma pessoa negra escravizada durante séculos nas plantações da América.

A necropolítica faz parte do projeto neoliberal, à medida que elimina os "excedentes". Porque a prisão foi uma alternativa; mas, diante de sua insuficiência. Um Estado não pode prender quase todo mundo e obrigar a trabalhar em regime escravo, essa saída foi usada pelo sistema estadunidense. Homens negros, na maioria dos casos, mas, também prendem as mulheres negras, passaram a ser presos por qualquer motivo após o fim da legalidade da escravidão. O documentário "13th" - que em português pode ser traduzido como 13 ${ }^{\mathbf{a}}$ (Décima terceira) -foi dirigido por Ava Duvernay (que também foi diretora do premiado "Selma"). O filme apresenta argumentos consistentes com documentação, imagens e relatos de diversos setores da sociedade que explicam os porquês

${ }^{53}$ AGAMBEN, Homo Sacer: O poder soberano e a vida nua, p. 16. 
da população negra dos Estados Unidos da América (EUA), mesmo representando apenas $13 \%$ do total de cidadãos, ser $40 \%$ dos usuários do sistema carcerário estadunidense. Essa desproporção tem relação direta com uma política de Estado, um tipo de "biopoder neoliberal”. O filme mostra o ex-presidente Bill Clinton empenhado em expandir os meios de encarcerar. Não foi à toa que a população carcerária dos EUA saltou de políticas de 357 mil pessoas em 1970 para 2,3 milhões em 2014 (DuVernay, 20). A 13ª Emenda, assinada em 08 de Abril de 1864, proibiu a escravização e servidão involuntária. Mas, incluiu um adendo: "salvo como punição de um crime pelo qual o réu tenha sido devidamente condenado" ${ }^{54}$

Dado que boa parte da população mundial é pobre demais para a imposição e cobrança de dívidas e, ao mesmo tempo, muito numerosa para o confinamento presidiário, o controle social precisa de outros meios. Em tempos de "devir-negro do mundo”, a necropolítica anti-negros se apresenta como o novo meio de eliminação.

\section{Referências}

AGAMBEN, Giorgio. Homo Sacer: O poder soberano e a vida nua. Tradução de Henrique Burigo. Belo Horizonte: Ed. UFMG, 2004.

FOUCAUlT, M. Nascimento da Biopolítica. Tradução de Pedro Elói Duarte. Lisboa: Edições 70, 2010.

FOUCAULT, M. É preciso defender a sociedade. Curso do Collége de France (1975-1976). Tradução de Carlos Correia M. de Oliveira. Lisboa: Livros, Brasil, 2006.

FOUCAUlT, M. Resumo dos Cursos do Collége de France (1970-1982). Tradução de Andréa Daher. Rio de Janeiro: Jorge Zahar, 1997.

HEGEL, G. Friedrich. Princípios de Filosofia do Direito. São Paulo: Martins Fontes, 1997.

MBEMBE, Achille. Necropolítica: Biopoder, soberania, estado de exceção, política da morte. Rio de Janeiro: n-1 edições, 2018.

MBEMBE, Achille. Crítica da Razão Negra. Lisboa: Antígona, 2014.

NASCIMENTO, A. O genocídio do negro brasileiro. Processo de um Racismo Mascarado. Rio de Janeiro: Editora Paz e Terra, 1978.

\footnotetext{
${ }_{54}$ Constituição dos Estados Unidos da América. No documento original constam apenas duas seções: 13th Amendment. Amendment XIII./ Section 1. Neither slavery nor involuntary servitude, except as a punishment for crime where of the party shall have been duly convicted, shall exist within the United States, or any place subject to their jurisdiction. Section 2. Congress shall have power to enforce this article by appropriate legislation.
} 
NOGUERA, Renato. Dos condenados da terra à necropolítica: diálogos filosóficos entre

Frantz Fanon e Achille Mbembe. Revista Latino Americana do Colégio Internacional de Filosofia, n. 3, 2016. 